\title{
Repair of Inferior Sternal Cleft Using Bilateral Sternal Bar Turnover Flaps in a Patient with Pentalogy of Cantrell
}

\author{
Hui-Ling Chia, Vincent Kok-Leng Yeow \\ Department of Plastic, Reconstructive and Aesthetic Surgery, KK Women's and Children's Hospital, Singapore
}

We report a case of sternal reconstruction using bilateral sternal bar turnover flaps in a 4-yearold boy with an inferior sternal cleft, as part of Cantrell's pentad. When the patient was 10 months old, he underwent sternal reconstruction using a resorbable poly-L-lactic-polyglycolic acid plate in the first stage when there was insufficient autogenous tissue to provide a reliable reconstruction. Bilateral sternal bar turnover was performed in the second stage at 4 years of age. This operative technique is described in this report. This novel technique provides a robust, dynamic, and reliable reconstruction for inferior sternal defects.

Keywords Pentalogy of Cantrell / Ectopia cordis
Correspondence: Hui-Ling Chia Department of Plastic, Reconstructive and Aesthetic Surgery, KK Women's and Children's Hospital, 100 Bukit Timah Road, Singapore 228899 Tel: $+65-9139-0179$

Fax: +65-6394-1524

E-mail: chiahuiling@gmail.com

No potential conflict of interest relevant to this article was reported.

\section{INTRODUCTION}

Pentalogy of Cantrell is a rare congenital anomaly with features of intra-cardiac defects and defects involving the lower sternum, midline abdominal wall, anterior diaphragm, and diaphragmatic pericardium [1]. The options for the repair of the inferior sternal cleft include the use of autologous tissue or alloplastic materials. Autogenous tissue is often preferred, as it is associated with fewer complications. In this report, we present a novel technique of using bilateral sternal bar turnover flaps for the reconstruction of a lower sternal cleft defect in a patient with pentalogy of Cantrell. During the first stage, when the child was only 10 months old and there was insufficient autogenous tissue to provide a reliable reconstruction, the cleft was repaired using a resorbable poly-Llactic-polyglycolic acid (PLLA-PGA) plate.

\section{CASE}

Our patient is a 4-year-old Indonesian Chinese boy, diagnosed with pentalogy of Cantrell. At 10 months of age, he required early corrective cardiac surgery due to deteriorating cardiopulmonary function, and the repair of sternal, diaphragmatic, and abdominal wall defects was planned at the same time. He had partial herniation of the heart through a lower sternal defect (ectopia cordis), which was only covered by thin skin, allowing the cardiac pulse to be seen (Fig. 1). Although autologous tissue was preferred over alloplastic material, the patient's native tissue was not adequate for a reliable reconstruction at that time. A staged procedure was planned, and a resorbable PLLA-PGA plate was implanted as a temporary shield over his heart in the first stage [2]. This provided a stable soft tissue cover over his heart for 3 years. We carried out the second stage of rigid sternal

Copyright $(\odot 2014$ The Korean Society of Plastic and Reconstructive Surgeons

This is an Open Access article distributed under the terms of the Creative Commons Attribution Non-Commercial License (http://creativecommons.org/

licenses/by-nc/3.0/) which permits unrestricted non-commercial use, distribution, and reproduction in any medium, provided the original work is properly cited.

www.e-aps.org 
reconstruction at 4 years of age, when the patient's thoracic skeleton had grown.

Our technique for reconstruction of the inferior sternal defect is as follows: the patient is placed in a supine position. A sagittal incision is made over the previous midline scar. Skin and pectoralis major muscle flaps are raised using fine needle diathermy, exposing the sternal bar and proximal costal cartilages (Fig. 2). The superior rectus attachments are dissected from the lower border of the sternal bar and ribs. Further, the cartilaginous sternal bars are bisected using a scalpel, along their length, from lateral to medial, leaving the medial perichondrium intact (Fig. 3). This allows the anterior half of the bisected sternal bars to be turned over medially to cover the inferior sternal defect. The cartilaginous flaps are sutured together in the midline using

\section{Fig. 1. Ectopia cordis}

A preoperative photograph of the patient at 10 months of age, showing abdomino-thoracic ectopia cordis. There is partial herniation of the heart through a lower sternal defect; this was covered by very thin skin, allowing the cardiac pulse to be seen. An epigastric hernia was also present.

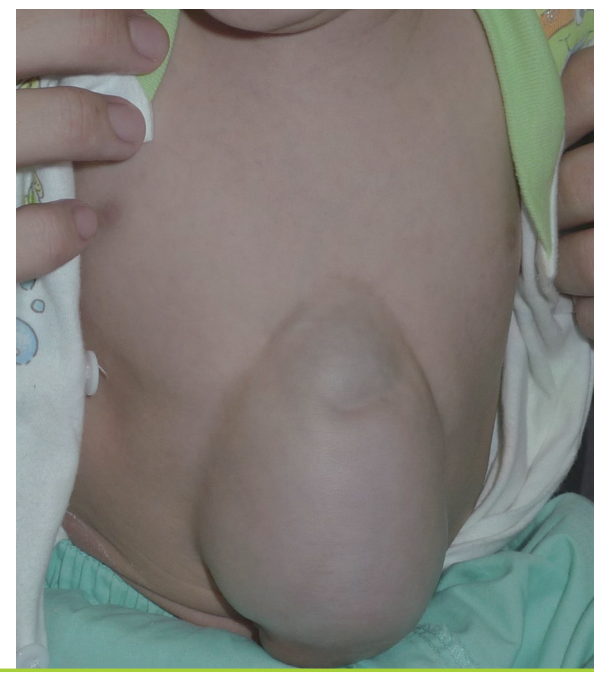

polypropylene sutures, constituting a complete thoracic skeletal ring (Fig. 4). After suture apposition of the divaricated superior rectus muscles with polyglactin sutures, the rectus muscles are re-attached to the reconstructed lower sternum using polypropylene sutures. For sustained postoperative pain control, $0.025 \%$ bupivacaine is administered using elastomeric infusors via two epidural catheters. These are placed under the sternal bars, one on each side. The bupivacaine will infuse at $2 \mathrm{~mL} / \mathrm{hr}$ over the next 48 hours. We place the drainage catheter over the sternal bars to avoid draining the infused bupivacaine solution. Further, bilateral pectoralis major flaps are advanced and sutured in the midline to cover the reconstructed sternum before skin closure.

The patient was admitted to a high dependency ward for 24 hours. The epidural infusion catheters were removed after 48 hours and the drainage catheter after 3 days. The patient remained relatively pain-free during the hospitalization and was discharged on postoperative day 5. The 10-month follow-up revealed that he was well and the reconstruction had remained rigid (Fig. 5). No complications were noted.

\section{DISCUSSION}

The principles for reconstruction of inferior sternal clefts include the following: 1) rigid protection of the heart without compression, 2) preferable use of autologous tissue, 3) dynamic reconstruction of the thoracic cage, 4) uncompromised growth, and 5) minimal donor site morbidity.

The options for reconstruction of congenital sternal defects include the use of autologous tissue or alloplastic materials. Autogenous tissue is recommended due to a relatively low risk of infection and extrusion, and its ability to remodel according to patient growth, as opposed to alloplastic materials. However, autologous reconstruction incurs donor site morbidity and is technically more difficult.

\section{Fig. 2. Inferior sternal cleft}

(A) Intraoperative photograph showing the inferior sternal cleft and separated upper rectus abdominis, forming a diamond-shaped defect. (B) Schematic representation.
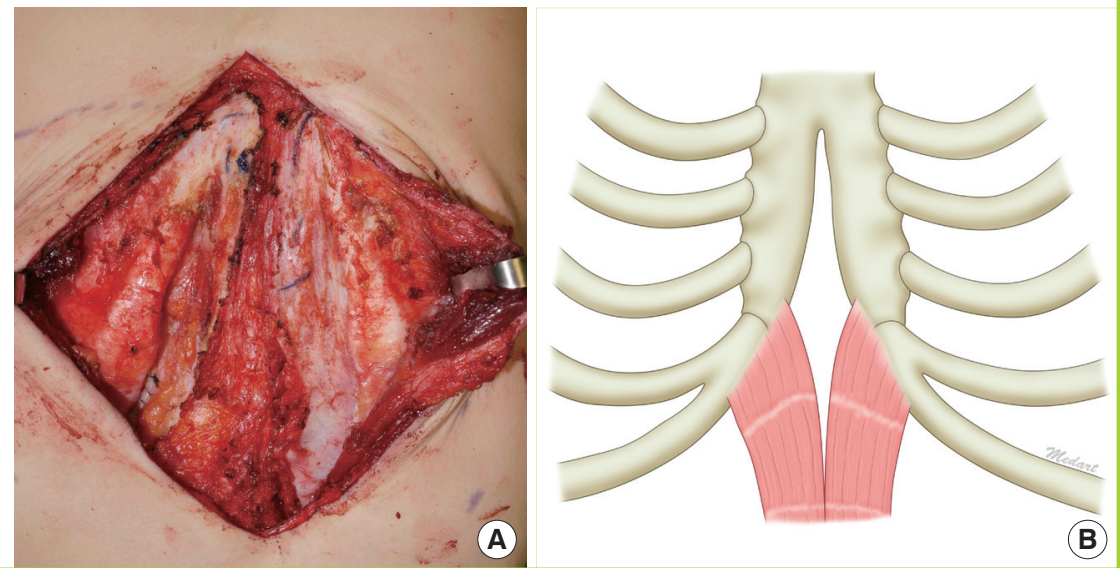


\section{Fig. 3. Bisection of sternal bars}

(A) The cartilaginous sternal bars are bisected along their length from lateral to medial, leaving the medial perichondrium intact. This allows the anterior half of the bisected sternal bars to be turned over medially to cover the inferior sternal defect. (B) Schematic representation.
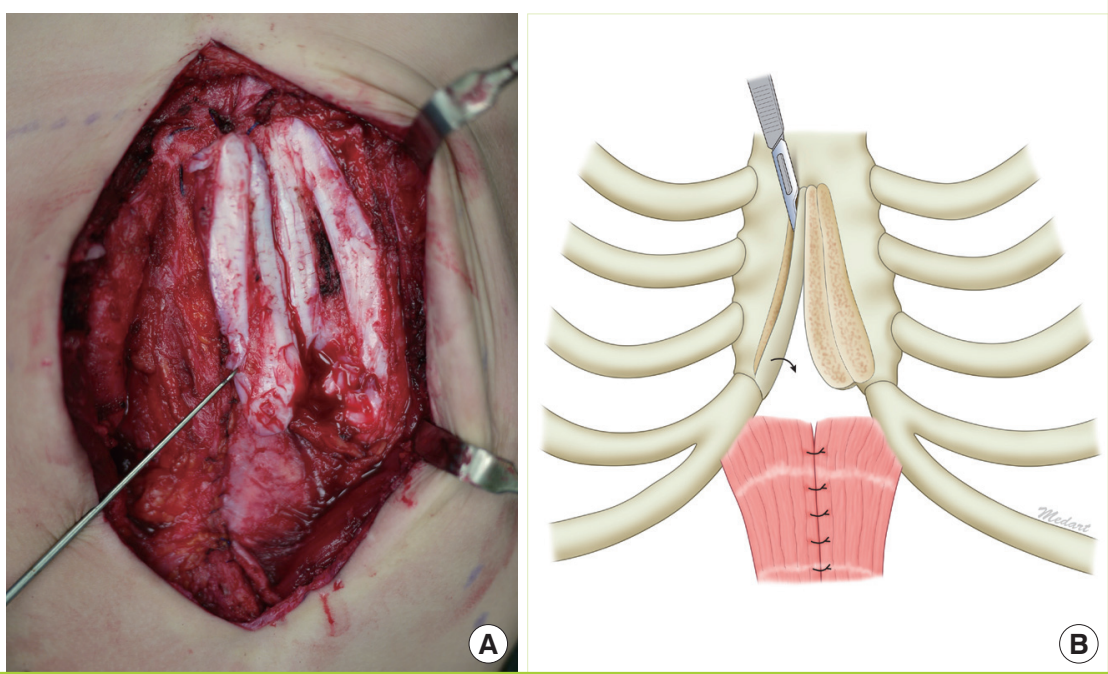

Fig. 4. Suture apposition of sternal bar flaps

(A) The cartilaginous flaps are sutured together in the midline using polypropylene sutures. The divaricated superior rectus muscles are apposed with polyglactin sutures and re-attached to the inferior sternal bar flaps using polypropylene sutures. (B) Schematic representation.
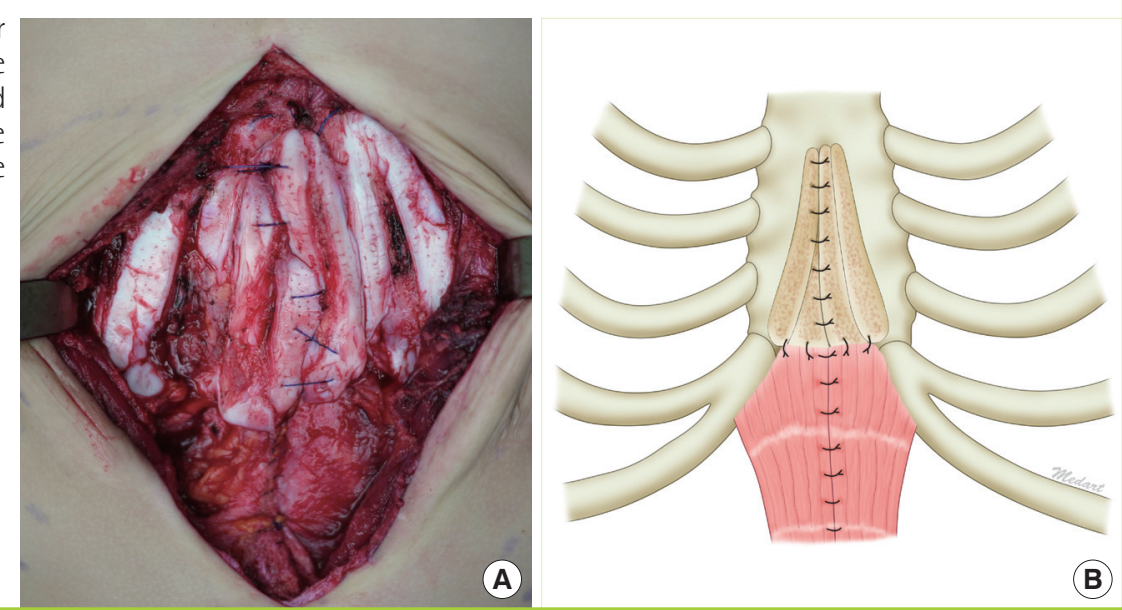

(A)

(B)

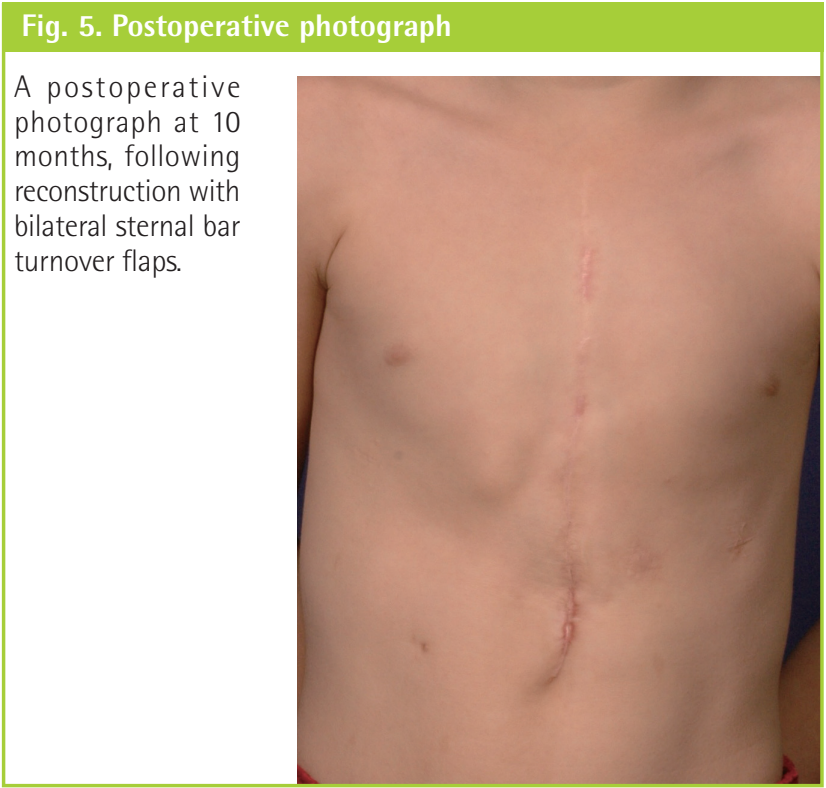

\begin{tabular}{|c|c|c|}
\hline & Local tissues & Regional tissues \\
\hline Thorax & $\begin{array}{l}\text { Rib grafts/struts } \\
\text { Sliding chondrotomies } \\
\text { Anterior perichondrial/posterior } \\
\text { sternal flaps } \\
\text { Bilateral sternal bar turnover } \\
\text { flaps }\end{array}$ & - \\
\hline Muscle & Pectoralis major flaps & $\begin{array}{l}\text { Latissimus dorsi } \\
\text { Rectus abdominis }\end{array}$ \\
\hline Composite & - & $\begin{array}{l}\text { Osteomuscular latissimus dorsi } \\
\text { composite flap }\end{array}$ \\
\hline
\end{tabular}

There are a number of autologous options for reconstructing sternal defects; these can be broadly classified into local and regional tissues (Table 1). Local options comprise mainly grafts or flaps that are harvested from the anterior thorax. Techniques 
include sliding chondrotomies, rib struts or grafts, and anterior perichondrial and posterior sternal flaps [3,4]. Bilateral pectoralis major advancement flaps are muscle flaps useful in the reinforcement of local reconstruction but are rarely sufficiently robust to be used alone. These techniques have the advantage of utilizing tissue in the vicinity of the reconstruction, obviating the need for a separate donor site. Regional options include the pedicled latissimus dorsi and rectus abdominis flaps. Although these flaps can provide sizeable coverage, they contain only soft tissue and can lead to significant donor site morbidity. To improve chest wall stability, the ninth and tenth ribs can be included to buttress the latissimus dorsi flap [5].

We planned a staged reconstruction for this patient, as his rib and sternal bar were not adequate for a robust reconstruction when he was an infant. A resorbable PLLA-PGA plate was used for repairing the lower sternal defect, acting as a temporary shield for the heart in the first stage [2]. Autologous reconstruction was deferred until the child's thoracic skeleton was more developed.

Bilateral sternal bar flaps have the advantage of providing a rigid reconstruction without significant donor site morbidity. The sternal bars found in patients with sternal clefts are often thick, and bisection allows a substantial increase in surface coverage without a significant compromise in the strength of the flaps. Fixation of the flaps in the midline restores skeletal continuity of the thoracic cage, creating a dynamic reconstruction. In cases where the extent of the flaps are short of the midline after a turnover, we propose combining this technique with sliding chondrotomies to increase the reach of the flaps [3]. For narrow clefts where turnover flaps overlap in the midline, thinner flaps may be raised, leaving behind thicker remnant sternal bars. Apart from lower sternal defects, it may be possible to use this technique correspondingly for other cleft deformities of the sternum, such as superior sternal clefts.

\section{REFERENCES}

1. Cantrell JR, Haller JA, Ravitch MM. A syndrome of congenital defects involving the abdominal wall, sternum, diaphragm, pericardium, and heart. Surg Gynecol Obstet 1958; 107:602-14.

2. Chia HL, Rasheed MZ, Ong KK, et al. Repair of ectopia cordis using a resorbable poly-L-lactic-polyglycolic acid plate in a patient with pentalogy of Cantrell. J Pediatr Surg 2012;47:e1-4.

3. de Campos JR, Filomeno LT, Fernandez A, et al. Repair of congenital sternal cleft in infants and adolescents. Ann Thorac Surg 1998;66:1151-4.

4. Jadhav V, Rao S, D’Cruz A. Autologous repair of isolated complete sternal cleft in an adolescent. J Pediatr Surg 2009; 44:2414-6.

5. Lampert JA, Harmaty M, Thompson EC, et al. Chest wall reconstruction in thoracoabdominal ectopia cordis: using the pedicled osteomuscular latissimus dorsi composite flap. Ann Plast Surg 2010;65:485-9. 